\title{
ANALISIS FAKTOR PENENTU KEPUASAN KERJA KARYAWAN HOTEL
}

\author{
Rachel Dyah Wiastuti ${ }^{(1)}$, Jenny Chandra ${ }^{(2)}$ \\ (1)(2) Hotel Management Department \\ Universitas Bina Nusantara \\ rwiastuti@binus.edu
}

Submitted: 5 September 2019 Revised: 28 September 2019

Accepted: 1 October 2019

\begin{abstract}
ABSTRAK
Penelitian ini bertujuan untuk mengetahui faktor yang menentukan kepuasan kerja karyawan Restoran Cinnamon di Hotel Mandarin Oriental Jakarta. Data didapatkan melalui survei menggunakan kuesioner dengan pernyataan tertutup dalam pilihan jawaban skala Likert. Wawancara juga dilakukan kepada karyawan sebagai data primer. Sampel penelitian adalah 36 karyawan Restoran Cinnamon, baik karyawan pada bagian pelayanan maupun bagian produksi. Deskriptif statistik digunakan untuk mengetahui faktor penentu kepuasan kerja, yang menunjukkan bahwa lingkungan kantor yang nyaman dan evaluasi sebagai pengambilan keputusan menjadi dua faktor utamanya. Sedangkan analisis faktor konfirmatori digunakan untuk mengkonfirmasi faktor penentu kepuasan kerja yang kemudian dikelompokkan menjadi enam faktor yaitu kompensasi dan dukungan, lingkungan dan peluang karir, evaluasi dan tanggung jawab, otonom, komunikasi dan konten pekerjaan. Implikasi penelitian ini untuk memberikan saran bagi manajemen hotel dalam memahami karyawan agar tercipta komitmen organisasi yang tinggi dan mengarah pada tingkat turnover yang rendah.
\end{abstract}

Kata Kunci : Faktor Kepuasan, Kepuasan, Kepuasan Kerja, Lingkungan Kerja

\section{FACTOR ANALYSIS OF EMPLOYEE JOB SATISFACTION AT HOTEL INDUSTRY}

\begin{abstract}
The objective of this research is to identify the determinant factors of employee job satisfaction at Cinnamon Restaurant, Mandarin Oriental Hotel, Jakarta. Data was collected through survey using questionnaires with close-ended statement and Likert scale. Additional interview was conducted to support the data. Sample of this research is 36 employees of Cinnamon Restaurant, production and service department. Descriptive statistic was used to determine the job satisfaction factors. It shows that workplace environment and evaluationbased decision- making become the two major factors that determine the employee satisfaction. While, confirmatory factor analysis was used to confirm the existing factor of employee satisfaction. As a result, six factors were formed and named as benefit and support, environment and career opportunities, evaluation and responsibility, autonomous, communication, and job content. This research implication provide suggestion for the hotel management to better understanding their employee to enhance the organizational commitment that lead to low turnover rate.
\end{abstract}

Keywords: Employee Satisfaction, Factor Analysis, Job Satisfaction, Working Environment 


\section{PENDAHULUAN}

Fanning dalam Compdata Surveys (2017) menyampaikan bahwa industri hospitality selalu berada pada posisi tertinggi baik dalam voluntary turnover maupun total tingkat turnover dibandingkan dengan industri lainnya. Terjadinya kenaikan dan ketidakstabilan turnover menjadi tantangan tersendiri bagi perusahaan (Munir \& Rahman, 2016). Turnover karyawan tidak dapat dipungkiri berpengaruh pada biaya dan kinerja sebuah perusahaan baik secara langsung maupun tidak langsung (AliAbadi, AliAkbar, \& Fathi, 2014).

Faktor kepuasan kerja diduga memegang peranan penting yang cukup signifikan dalam mempengaruhi turnover karyawan (Saputro, Fathoni, \& Minarsih, 2016). Berdasarkan literatur Mobley, \& Porter serta Steers, Price \& Mueller (dalam Munir \& Rahman, 2016), kepuasan kerja merupakan alasan utama seorang karyawan meninggalkan sebuah perusahaan. Kepuasan kerja yang tinggi mengacu terhadap rendahnya ketidakhadiran dan turnover (Dando, Abate, \& Mola, 2017). Selain itu, kepuasan kerja merupakan salah satu kunci utama yang memotivasi karyawan untuk bertahan pada sebuah perusahaan (An, Cha, Moon, Ruggiero, \& Jang, 2014).

Karyawan yang merasa puas terhadap pekerjaannya akan memiliki komitmen yang tinggi terhadap pekerjaan dan perusahaannya (Badriyah, 2015). Sebaliknya, ketidakpuasan kerja akan berdampak pada penurunan semangat kerja, begitu juga dengan semangat kerja yang rendah akan berdampak kepada turunnya loyalitas dan komitmen seorang individu pada sebuah perusahaan (Badriyah, 2015).

Ketidakpuasan kerja merupakan salah satu alasan utama yang menyebabkan terjadinya turnover yang disebabkan oleh penurunan komitmen sehingga seorang individu akan mencari peluang untuk berhenti dari pekerjaannya (Hashim, 2015).

Penelitian yang dilakukan oleh Dando et al. (2017); AliAbadi et al. (2014); Masum et al. (2015); c et al. (2013) juga menitikberatkan pada faktor-faktor yang menentukan kepuasan kerja sebagai pendorong utama sebuah perusahaan agar memiliki karyawan yang berkomitmen tinggi terhadap organisasi.

Oleh karena itu, kepuasan kerja menjadi salah satu faktor utama yang berpengaruh pada masa kerja seorang karyawan, maka kepuasan kerja menjadi komponen penting yang harus diperhatikan oleh sebuah perusahaan, karena karyawan yang puas akan bekerja lebih baik dan dapat membantu lebih maksimal dalam pencapaian visi dan misi perusahaan (Masum, Azad, \& Beh, 2015).

Tujuan penelitian ini adalah untuk mengetahui faktor utama yang menentukan kepuasan kerja karyawan pada Restoran Cinnamon di Hotel Mandarin Oriental, Jakarta dan untuk mengelompokkan indikator penentu kepuasan kerja karyawan.

\section{TINJAUAN PUSTAKA Komitmen Organisasi}

Atribut komitmen organisasional mengacu pada sejauh mana seorang individu menganggap dirinya sebagai seorang yang berorganisasi. Hal ini dapat didefinisikan sebagai keadaan psikologis yang mengikat individu ke organisasi (Einolander, 2015).

Komitmen organisasi yang telah diterima secara luas dapat membawa keuntungan bagi organisasi maupun karyawan itu sendiri dikarenakan dapat memperkuat perasaan kepemilikan, keamanan pekerjaan, perkembangan karir, peningkatan kompensasi dan penghargaan intrinsik yang lebih tinggi (Azeem \& Akhtar, 2014).

Hartono \& Setiawan (2013) berpendapat bahwa dengan adanya komitmen organisasi dari seorang karyawan dapat memunculkan peningkatan kepuasan kerja karyawan, kepuasan kerja akan lebih baik ketika karyawan dalam suatu organisasi memiliki komitmen organisasi yang tinggi sehingga mereka dapat bekerjasama dengn baik dan nyaman. 


\section{Kepuasan Kerja}

Kepuasan kerja merupakan hasil dari harapan dan pengalaman dari pekerjaan, bersifat subjektif dan spesifik. Kepuasan kerja akan muncul ketika perbedaan antara harapan dan pengalaman rendah dan memiliki versa yang bagus (Pan, 2015). Kepuasan kerja melibatkan perasaan suka, tidak suka serta kebutuhan intrinsik dan ekstrinsik seseorang (Dando, Abate, \& Mola, 2017). Kepuasan kerja mengacu kepada perilaku umum karyawan terhadap pekerjaannya dan lingkungan sosial psikologikal berkaitan dengan dimensi pekerjaan (Pattnaik \& Suvadarshini, 2015). Keberhasilan sebuah organisasi sangat bergantung dari kualitas dan kinerja individu yang ada dalam organisasi (Darmawati, Hidayati, \& Herlina, 2013). Oleh karena itu kepuasan kerja menjadi salah satu faktor utama yang berpengaruh pada masa kerja seorang karyawan, faktor kepuasan kerja menjadi komponen penting yang harus diperhatikan oleh sebuah perusahaan, karena karyawan yang puas akan bekerja lebih baik dan dapat membantu lebih maksimal dalam pencapaian visi dan misi perusahaan (Masum, Azad, \& Beh, 2015).

Menurut Olivers' Cognitive Model dalam Pan (2015), faktor yang menjadi penentu kepuasan kerja terdiri dari 26 indikator yang diklasifikasikan ke dalam enam dimensi. Keenam dimensi tersebut yaitu evaluasi dan promosi, kompensasi dan tunjangan, konten pekerjaan, lingkungan kerja, pimpinan, dan hubungan interpersonal (Pan, 2015). Terdapat empat hipotesis dalam penelitian ini, yaitu:

- H1: Faktor utama yang menentukan kepuasan kerja karyawan Restoran Cinnamon, Mandarin Oriental, Jakarta pada departemen kitchen berbeda dengan departemen food and beverage service.

- H2: Faktor utama yang menentukan kepuasan kerja pada karyawan Restoran Cinnamon, Mandarin Oriental, Jakarta berbeda antara pria dan wanita.
- H3: Faktor utama yang menentukan kepuasan kerja pada karyawan Restoran Cinnamon, Mandarin Oriental, Jakarta berbeda berdasarkan rentang usia.

- H4: Faktor utama yang menentukan kepuasan kerja pada karyawan Restoran Cinnamon, Mandarin Oriental, Jakarta sama berdasarkan tingkat pendidikan.

\section{METODE}

Jenis penelitian yang digunakan adalah penelitian deskriptif. Penelitian deskriptif bertujuan untuk mengumpulkan data yang dapat mendeskripsikan karakteristik seseorang, sesuatu maupun situasi (Sekaran \& Bougie, 2013). Penelitian deskriptif tepat digunakan untuk meneliti masalah yang membutuhkan studi yang mendalam (Bungin, 2017).

\section{Populasi, Sampel dan Pilot Study}

Objek dalam penelitian ini adalah Restoran Cinnamon yang merupakan International All - Day Dining Restaurant di Mandarin Oriental Hotel, Jakarta. Populasi penelitian adalah seluruh karyawan Restoran Cinnamon di Mandarin Oriental Hotel, baik departemen kitchen maupun food and beverage services yang berjumlah 36 orang. Teknik pengambilan sampel yaitu nonprobability sampling dan sampling jenuh, yang tidak memberi peluang yang sama bagi setiap populasi untuk dipilih menjadi sampel dengan kondisi jumlah populasi yang relative kecil (Sujarweni, 2014).

Pilot study dilakukan kepada 18 responden yang merupakan $50 \%$ dari total sampel pada 26 Mei 2018 dan 7 Juni 2018. Pilot study dibutuhkan untuk menguji serta merevisi materi penelitian setelah peneliti melakukan uji validitas dan reliabilitas (Eldridge, et al., 2016). Hasil olah data menunjukkan bahwa 31 butir pertanyaan kuisioner memiliki $\mathrm{r}$ hitung dengan nominal yang lebih besar dari $r$ tabel (0.4683), sehingga dapat disimpulkan bahwa seluruh butir kuisioner dinyatakan valid (Siregar, 
2015). Sedangkan hasil Cronbach's Alpha kuisioner memiliki nilai koefisien reliabilitas yang lebih besar dari 0.6 , sehingga dapat disimpulkan seluruh butir kuisioner dinyatakan reliabel (Siregar, 2015).

\section{Teknik Pengumpulan Data}

Data primer didapatkan melalui survei menggunakan kuisioner dan wawancara. Kuisioner disebarkan secara langsung dan dibagikan kepada responden pada 26 Mei 2018 - 15 Juni 2018. Kuisioner penelitian terdiri dari dua bagian. Bagian pertama terdiri profil responden yaitu jenis kelamin, departemen tempat karyawan bekerja, usia, dan pendidikan terakhir. Bagian kedua terdiri dari 31 pertanyaan tertutup tentang kepuasan kerja berdasarkan teori Olivers' Cognitive Model dalam Pan (2015). Pilihan jawaban menggunakan skala Likert dimana skala 5 untuk sangat setuju, 4 untuk setuju, 3 untuk netral, 2 untuk tidak setuju dan 1 untuk sangat tidak setuju (Sudaryono, 2016). Wawancara dilakukan pada 26 Juni 2018 kepada 3. responden dengan menggunakan pertanyaan terbuka dengan tujuan untuk mengetahui tanggapan responden terhadap faktor penentu kepuasan kerja berdasarkan pendapat pribadi. Data sekunder didapatkan dari jurnal nasional, jurnal internasional, publikasi yang didapatkan melalui internet, buku fisik serta penelitian terdahulu.

\section{HASIL DAN PEMBAHASAN Profil Responden}

Berdasarkan Tabel 1, mayoritas responden yang merupakan karyawan Restoran Cinnamon adalah laki - laki (72.2\%), departemen food and beverage services (52.8\%), berusia 25 - 30 tahun (44.4\%) dengan tingkat pendidikan terakhir SMA/ SMK (50\%) dan masa kerja dibawah satu tahun $(44.4 \%)$ yang sebagian besar berdomisili di Jakarta (72.2\%). Responden berasal dari kelompok yang terbagi atas dua departemen yaitu food and beverage services sebanyak 19 orang $(52.8 \%)$ dan kitchen sebanyak 17 orang $(47.2 \%)$.

Tabel 1. Profil Responden

\begin{tabular}{llcc}
\hline \multicolumn{1}{c}{ Kategori } & \multicolumn{1}{c}{ Jawaban } & n & $\mathbf{( \% )}$ \\
\hline Jenis kelamin & Laki - Laki & 26 & 72.2 \\
& Perempuan & 10 & 27.8 \\
\hline Departemen & Food and Beverage & 19 & 52.8 \\
& $\begin{array}{l}\text { Services } \\
\text { Kitchen }\end{array}$ & 17 & 47.2 \\
& < 25 Tahun & 11 & 30.6 \\
& 25 - 30 Tahun & 16 & 44.4 \\
Usia & 31 - 35 Tahun & 7 & 19.4 \\
& 36 - 40 Tahun & 1 & 2.8 \\
& >40 Tahun & 1 & 2.8 \\
\hline Pendidikan & SMA/ SMK & 18 & 50 \\
& Diploma 1, 2, 3 & 16 & 44.4 \\
& Diploma IV/ S1 & 2 & 5.6 \\
\hline Lama masa & $<1$ tahun & 16 & 44.4 \\
kerja di & 1-2 tahun & 8 & 22.2 \\
Mandarin & 2-3 tahun & 3 & 8.3 \\
Oriental & 3-4 tahun & 3 & 8.3 \\
& $>4$ tahun & 6 & 16.7 \\
& & & \\
\hline
\end{tabular}




\begin{tabular}{clcc}
\hline Kategori & \multicolumn{1}{c}{ Jawaban } & n & $\mathbf{( \% )}$ \\
\hline Domisili & Jakarta & 26 & 72.2 \\
& Bogor & 2 & 5.6 \\
& Depok & 3 & 8.3 \\
& Tangerang & 3 & 8.3 \\
& Bekasi & 2 & 5.6 \\
\hline
\end{tabular}

\section{Sumber : Olahan peneliti 2018}

\section{Deskripif Statistik Faktor Penentu Kepuasan Kerja}

Tabel 2 menunjukkan deskriptif statistik faktor penentu kepuasan kerja, dimana nilai deviasi menunjukkan bahwa tanggapan responden beragam terhadap setiap indikator kuesioner. Dimensi pertama dari kepuasan kerja yaitu evaluasi dan promosi memperoleh nilai rata - rata sebesar 4.07 yang artinya responden setuju bahwa evaluasi dan promosi menjadi faktor penentu kepuasan kerja. Pada dimensi evaluasi dan promosi, responden menyatakan netral cenderung setuju terhadap indikator evaluasi penilaian kinerja dilaksanakan secara berkala dan hasil evaluasi sebagai motivasi perbaikan dan peningkatan kinerja. Responden menyatakan setuju pada indikator evaluasi dan peluang promosi yang adil, evaluasi sebagai pengambilan keputusan dan kriteria dengan metode yang benar, serta adanya peluang perkembangan karir.

Dimensi kedua dari kepuasan kerja yaitu kompensasi dan tunjangan memperoleh nilai rata- rata sebesar 3.91 yang artinya responden netral cenderung setuju bahwa kompensasi dan tunjangan menjadi faktor penentu kepuasan kerja. Pada dimensi kompensasi dan tunjangan, reponden menyatakan setuju dengan indikator sistem kompensasi yang adil dan jumlah tunjangan sesuai standar peraturan pemerintah. Responden menyatakan netral cenderung setuju terhadap indikator bonus berdasarkan kinerja, kesesuaian gaji dengan kinerja dan posisi pekerjaan, terdapat program pelatihan kerja dan kesesuaian pekerjaan dengan pelatihan kerja.

\section{Tabel 2. Deskriptif Statistik Faktor Penentu Kepuasan Kerja}

\begin{tabular}{|c|c|c|c|}
\hline Dimensi & Indikator & $\begin{array}{l}\text { Std. } \\
\text { Dev }\end{array}$ & Mean \\
\hline \multirow{7}{*}{$\begin{array}{r}\text { Evaluasi } \\
\text { dan Promosi } \\
4.07\end{array}$} & $\begin{array}{l}\bullet \text { Evaluasi penilaian kinerja dilaksanakan secara } \\
\text { berkala }\end{array}$ & 1.170 & 3.94 \\
\hline & $\begin{array}{l}\text { - Evaluasi yang adil dalam penilaian kinerja } \\
\text { tahunan }\end{array}$ & 1.063 & 4.11 \\
\hline & - Peluang promosi yang adil & 1.134 & 4.17 \\
\hline & - Kriteria evaluasi dengan metode yang benar & 0.910 & 4.03 \\
\hline & - Evaluasi sebagai pengambilan keputusan & 0.668 & 4.19 \\
\hline & $\begin{array}{l}\text { - Hasil evaluasi sebagai motivasi perbaikan dan } \\
\text { peningkatan kinerja }\end{array}$ & 1.028 & 3.97 \\
\hline & - Peluang perkembangan karir & 1.068 & 4.06 \\
\hline \multirow{5}{*}{$\begin{array}{l}\text { Kompensas } \\
\text { i dan } \\
\text { Tunjangan } \\
\mathbf{3 . 9 1}\end{array}$} & - Sistem kompensasi yang adil & 1.099 & 4.14 \\
\hline & $\begin{array}{l}\text { - Jumlah tunjangan sesuai standar peraturan } \\
\text { pemerintah }\end{array}$ & 0.971 & 4.03 \\
\hline & - Bonus berdasarkan kinerja & 1.261 & 3.69 \\
\hline & - Kesesuaian gaji dengan kinerja & 1.134 & 3.83 \\
\hline & - Kesesuaian gaji dengan posisi pekerjaan & 1.046 & 3.86 \\
\hline
\end{tabular}




\begin{tabular}{|c|c|c|c|}
\hline Dimensi & Indikator & $\begin{array}{l}\text { Std. } \\
\text { Dev }\end{array}$ & Mean \\
\hline & - Terdapat program pelatihan kerja & 1.052 & 3.92 \\
\hline & - Kesesuaian pekerjaan dengan pelatihan kerja & 0.967 & 3.92 \\
\hline \multirow{8}{*}{$\begin{array}{c}\text { Konten } \\
\text { Pekerjaan } \\
\text { 3.89 }\end{array}$} & - Diberikan kemandirian dalam bekerja & 0.951 & 3.81 \\
\hline & - Tanggung jawab yang dimiliki atau diemban & 1.014 & 4.00 \\
\hline & - Tugas dan tanggung jawab yang bervariasi & 1.045 & 3.78 \\
\hline & - Pencapaian hasil kinerja sesuai standar & 1.073 & 3.86 \\
\hline & - Hasil pekerjaan yang berguna bagi perusahaan & 0.919 & 3.89 \\
\hline & - Peluang mempelajari pekerjaan sesuai skill & 1.055 & 4.03 \\
\hline & - Peluang beradaptasi dengan pekerjaan & 0.926 & 4.00 \\
\hline & - Apresiasi atau pengakuan hasil kerja & 1.105 & 3.75 \\
\hline \multirow{4}{*}{$\begin{array}{c}\text { Lingkunga } \\
\text { n Kerja } \\
4.13 \\
\text { Pimpinan } \\
3.92\end{array}$} & - Lingkungan kantor yang nyaman & 0.980 & 4.19 \\
\hline & - Keamanan atau kestabilan kondisi perusahaan & 1.094 & 4.06 \\
\hline & $\begin{array}{l}\text { • Instruksi pimpinan yang jelas dalam penyelesaian } \\
\text { pekerjaan }\end{array}$ & 1.141 & 3.89 \\
\hline & - Dukungan pimpinan dalam pemecahan masalah & 1.040 & 3.94 \\
\hline \multirow{5}{*}{$\begin{array}{c}\text { Hubungan } \\
\text { Interpersonal } \\
\mathbf{3 . 9 7}\end{array}$} & - Komunikasi yang jelas secara verbal & 1.025 & 4.08 \\
\hline & - Komunikasi yang jelas secara nonverbal & 0.986 & 4.00 \\
\hline & $\begin{array}{l}\text { - Dukungan rekan kerja dalam penyelesaian } \\
\text { konflik atau masalah }\end{array}$ & 0.841 & 4.08 \\
\hline & $\begin{array}{l}\text { • Kerjasama dan dukungan rekan kerja sesama } \\
\text { departemen }\end{array}$ & 0.924 & 3.94 \\
\hline & $\begin{array}{l}\text { • Kerjasama dan dukungan rekan kerja dari } \\
\text { departemen lain }\end{array}$ & 1.079 & 3.75 \\
\hline
\end{tabular}

\section{Sumber : Olahan peneliti 2018}

Dimensi ketiga dari kepuasan kerja yaitu konten pekerjaan memperoleh nilai rata- rata sebesar 3.89 yang artinya responden netral cenderung setuju bahwa konten pekerjaan menjadi faktor penentu kepuasan kerja. Pada dimensi konten pekerjaan, responden menyatakan setuju dengan tanggung jawab yang diemban, peluang mempelajari skill sesuai pekerjaan dan peluang beradaptasi dengan pekerjaan. Responden menyatakan netral cenderung setuju terhadap indikator diberikan kemandirian dalam bekerja, tugas dan tanggung jawab yang bervariasi, pencapaian hasil kinerja sesuai standar, hasil pekerjaan yang berguna bagi perusahaan dan apresiasi atau pengakuan hasil kerja. Responden A (2018) beranggapan bahwa peluang mempelajari sesuai skill menjadi paling penting karena dapat belajar demi menambah wawasan dan meningkatkan ketrampilan kerja. Inilah yang nantinya akan dapat meningkatkan kompetensi. Kompetensi sangat berguna untuk menyelesaikan pekerjaan, khusunya pekerjaan di bidang perhotelan (Alhamdi, 2018).

Dimensi keempat yaitu lingkungan kerja memperoleh nilai rata-rata sebesar 4.13 yang artinya responden setuju bahwa lingkungan kerja sebagai faktor penentu kepuasan kerja. Pada dimensi lingkungan kerja, responden menyatakan setuju terhadap indikator lingkungan kantor yang aman dan keamanan atau kestabilan kondisi perusahaan. Responden C (2018) berpendapat bahwa lingkungan kerja menjadi faktor utama penentu kepuasan kerja yang dikarenakan oleh lingkungan kerja yang nyaman dapat membuat karyawan lebih termotivasi untuk berusaha bekerja dengan maksimal. Ketika lingkungan kerja tidak nyaman, maka dapat menyebabkan karyawan yang bekerja menjadi kurang termotivasi untuk memulai pekerjaan dan bekerja secara maksimal.

Dimensi kelima yaitu pimpinan memperoleh nilai rata-rata sebesar 3.92 yang artinya responden netral cenderung 


\section{Rachel Dyah Wiastuti dan Jenny Chandra: ANALISIS FAKTOR PENENTU KEPUASAN KERJA KARYAWAN HOTEL}

setuju bahwa pimpinan sebagai faktor penentu kepuasan kerja. Pada dimensi pimpinan, responden menyatakan netral cenderung setuju terhadap indikator instruksi pimpinan yang jelas dalam penyelesaian pekerjaan dan dukungan pimpinan dalam pemecahan masalah.

Dimensi keenam yaitu hubungan interpersonal memperoleh nilai rata- rata 3.97 yang artinya responden netral cenderung setuju bahwa hubungan interpersonal menjadi faktor penentu kepuasan kerja. Pada dimensi hubungan interpersonal, responden menyatakan netral cenderung setuju terhadap indikator kerjasama dan dukungan rekan kerja antara sesama departemen dan dengan departemen lain. Responden menyatakan setuju terhadap indikator komunikasi yang jelas secara verbal dan nonverbal, serta dukungan rekan kerja dalam penyelesaian konflik atau masalah. Responden B (2018) mengungkapkan bahwa dukungan antar rekan kerja menjadi penting sebagai penentu kepuasan kerja karena tanpa dukungan antar rekan kerja, maka pekerjaan tidak akan terselesaikan dengan baik dan maksimal sehingga atasan, tamu dan bahkan karyawan itu sendiri tidak akan merasa puas terhadap hasil dari pekerjaannya.

\section{Faktor Penentu Kepuasan Kerja}

\section{Berdasarkan Departemen}

Gambar 1 menunjukkan bahwa faktor utama penentu kepuasan kerja karyawan Restoran Cinnamon yang bekerja pada departemen kitchen adalah evaluasi sebagai pengambilan keputusan keputusan (evaluasi dan promosi). Sedangkan bagi yang bekerja pada food and beverage service peluang mempelajari pekerjaan sesuai skill menjadi faktor utama. Skill menjadi hal yang penting karena peranan skill yang dimiliki waiter dan waitress ketika memberikan pelayanan makanan dan minuman di restoran sangat berdampak secara langsung kepada kepuasan tamu (Earlike \& Atalina, 2016). Untuk menguji hipotesis penelitian $\mathrm{H} 1$, oleh karena faktor penentu kepuasan kerja karyawan departemen kitchen dan food and beverage berbeda, maka keputusan yang diambil adalah $\mathrm{H} 1$ diterima yaitu, faktor utama yang menentukan kepuasan kerja karyawan Restoran Cinnamon, Mandarin Oriental, Jakarta pada departemen kitchen berbeda dengan departemen food and beverage service.

Faktor Penentu Kepuasan Kerja

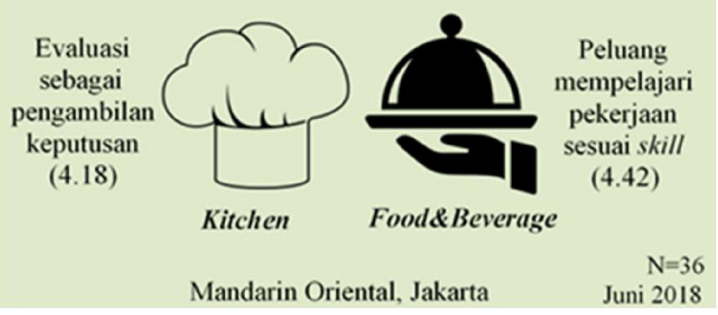

Gambar 1. Faktor Kepuasan Kerja Berdasarkan Departemen

Sumber: Olahan penulis 2018

Faktor Penentu Kepuasan Kerja Berdasarkan Jenis Kelamin

Gambar 2 menunjukkan bahwa faktor utama penentu kepuasan kerja karyawan pria Restoran Cinnamon adalah lingkungan kantor yang nyaman (lingkungan kerja). Sedangkan bagi karyawan wanita adalah evaluasi penilaian kinerja dilaksanakan secara berkala (evaluasi dan promosi). Untuk menguji hipotesis penelitian $\mathrm{H} 2$, oleh karena faktor penentu kepuasan kerja karyawan jenis kelamin pria dan wanita berbeda, maka keputusan yang diambil adalah $\mathrm{H} 2$ diterima yaitu, faktor utama yang menentukan kepuasan kerja karyawan Restoran Cinnamon, Mandarin Oriental, Jakarta berbeda antara pria dan wanita.

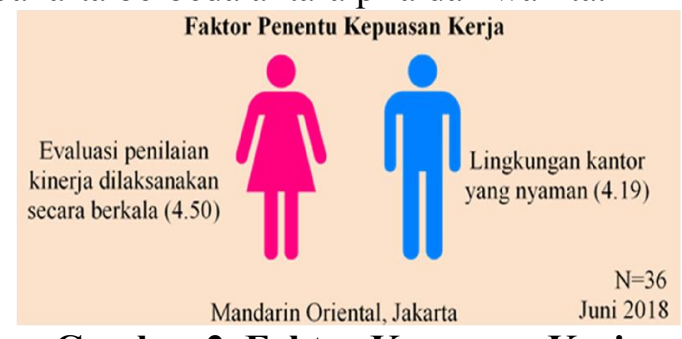

Gambar 2. Faktor Kepuasan Kerja Berdasarkan Jenis Kelamin

Sumber: Olahan penulis 2018 


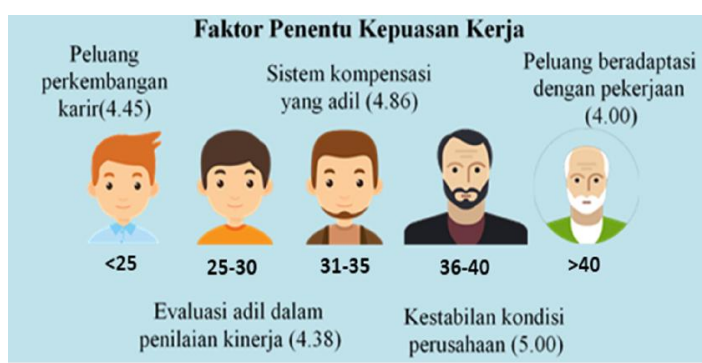

Gambar 3. Faktor Kepuasan Kerja Berdasarkan Usia

Sumber: Olahan penulis 2018

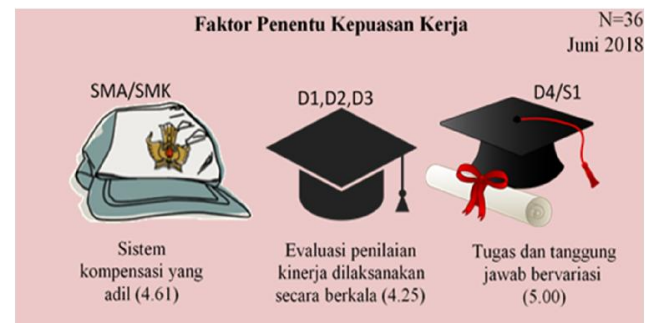

Gambar 4. Faktor Kepuasan Kerja Berdasarkan Pendidikan

Sumber: Olahan penulis 2018

\section{Faktor Penentu Kepuasan Kerja} Berdasarkan Usia

Gambar 3 menunjukkan bahwa faktor utama penentu kepuasan kerja karyawan Restoran Cinnamon adalah peluang perkembangan karir dan lingkungan kantor yang nyaman ( $<25$ tahun), evaluasi yang adil dalam penilaian kinerja tahunan (25-30 tahun), sistem kompensasi yang adil (31-35 tahun), kestabilan kondisi perusahaan (36-40 tahun), dan peluang beradaptasi dengan pekerjaan ( $>40$ tahun). Untuk menguji hipotesis penelitian $\mathrm{H} 3$, oleh karena faktor penentu kepuasan kerja karyawan berbeda berdasarkan rentang usia, maka keputusan yang diambil adalah $\mathrm{H} 3$ diterima yaitu, faktor utama yang menentukan kepuasan kerja karyawan Restoran Cinnamon, Mandarin Oriental, Jakarta berbeda berdasarkan rentang usia.

\section{Faktor Penentu Kepuasan Kerja Berdasarkan Pendidikan}

Gambar 4 menunjukkan bahwa faktor utama penentu kepuasan kerja karyawan Restoran Cinnamon adalah sistem kompensasi yang adil (kompensasi dan tunjangan) bagi lulusan SMA, evaluasi penilaian kinerja secara berkala (evaluasi dan promosi) bagi lulusan Diploma, serta tugas dan tanggung jawab yang bervariasi (konten pekerjaan) bagi lulusan D4/ S1. Untuk menguji hipotesis penelitian $\mathrm{H} 4$, oleh karena faktor penentu kepuasan kerja karyawan berbeda berdasarkan tingkat pendidikan, maka keputusan yang diambil adalah $\mathrm{H} 4$ ditolak yaitu, faktor utama yang menentukan kepuasan kerja karyawan Restoran Cinnamon, Mandarin Oriental, Jakarta sama berdasarkan tingkat pendidikan.

\section{Analisis Faktor Konfirmatori Terhadap Faktor Penentu Kepuasan Kerja}

Tabel 3 menunjukkan bahwa indikator dan sampel pada penelitian telah layak dan bisa diuji dengan analisis faktor. Hal ini dapat dilihat bahwa hasil KMO and Bartlett's Test adalah $0.569(>0.5)$ dengan signifikansi $0.000(<0.05)$. Standar sebuah variabel dan sampel dapat dianalisis dengan analisis faktor adalah dengan tingkat KMO and Bartlett's Test $>0.5$ dan signifikansi $<0.05$.

\section{Tabel 3. Uji Analisis Faktor: Hasil KMO and Bartlett's Test}

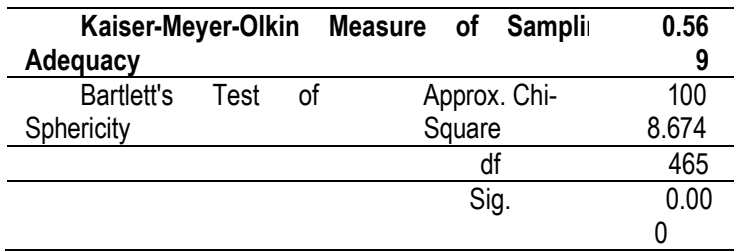

Sumber : Olahan penulis 2018

\section{Penentuan Jumlah Faktor dan Communalities}

Analisis ini bertujuan untuk menunjukkan angka korelasi antara indikator tertentu dengan faktor yang terbentuk. Jumlah faktor yang ditentukan adalah sebanyak enam faktor sesuai dengan teori yang telah ada. Besar communalities yang disarankan adalah 0.5 yang berarti bahwa korelasi cukup kuat antara indikator dan 
faktor yang terbentuk. Berdasarkan hasil olah data, seluruh indikator penelitian (X1X31) memiliki nilai communalities diatas 0.5 yang berarti korelasi antara indikator dengan faktor yang akan terbentuk cukup kuat. Nilai communalities tertinggi adalah indikator X27 (0.898).

\section{Uji Total Variance Explained}

Uji ini bertujuan untuk melihat total eigenvalues pada faktor yang terbentuk yang dapat dilihat pada Tabel 4. Faktor 1, Faktor 2, Faktor 3, Faktor 4, Faktor 4 dan Faktor 6 memiliki nilai eigenvalues $>1$ dengan total $72.23 \%$ dimana total cummulative $>50 \%$ tergolong cukup baik. Faktor 7 dan Faktor 8 juga memiliki nilai eigenvalues $>1$ namun tidak dinalisis lebih lanjut karena penentuan faktor yang dipilih adalah enam faktor sehingga dapat berpengaruh saat melakukan analisis sebaran indikator.

Tabel 4. Uji Analisis Faktor: Total Variance Explained

\begin{tabular}{|c|c|c|c|c|c|c|c|c|c|}
\hline \multicolumn{10}{|c|}{ Total Variance Explained } \\
\hline \multirow[b]{2}{*}{ Com } & \multicolumn{3}{|c|}{ Initial Eigenvalues } & \multicolumn{3}{|c|}{ Extraction Sums of Squared Loadings } & \multicolumn{3}{|c|}{ Rotation Sums of Squared Loadings } \\
\hline & Total & $\begin{array}{l}\% \text { of } \\
\text { Variance }\end{array}$ & $\begin{array}{l}\text { Cumulative } \\
\%\end{array}$ & Total & $\begin{array}{l}\% \text { of } \\
\text { Variance }\end{array}$ & $\begin{array}{l}\text { Cumulative } \\
\%\end{array}$ & Total & $\begin{array}{l}\% \text { of } \\
\text { Variance }\end{array}$ & Cumulative \% \\
\hline 1 & 12.100 & 39.031 & 39.031 & 12.100 & 39.031 & 39.031 & 5.207 & 16.796 & 16.796 \\
\hline 2 & 2.834 & 9.141 & 48.172 & 2.834 & 9.141 & 48.172 & 4.620 & 14.903 & 31.699 \\
\hline 3 & 2.199 & 7.093 & 55.265 & 2.199 & 7.093 & 55.265 & 3.750 & 12.095 & 43.794 \\
\hline 4 & 1.958 & 6.317 & 61.582 & 1.958 & 6.317 & 61.582 & 3.016 & 9.728 & 53.522 \\
\hline 5 & 1.852 & 5.973 & 67.555 & 1.852 & 5.973 & 67.555 & 2.933 & 9.461 & 62.983 \\
\hline 6 & 1.455 & 4.694 & 72.248 & 1.455 & 4.694 & 72.248 & 2.872 & 9.265 & 72.248 \\
\hline 7 & 1.382 & 4.459 & 76.707 & & & & & & \\
\hline 8 & 1.086 & 3.503 & 80.210 & & & & & & \\
\hline
\end{tabular}

\section{Sumber : Olahan peneliti 2018}

Component Matrix dan Rotation Matrix

Faktor penentu kepuasan kerja yang telah melalui proses faktoring dengan analisis faktor konfirmatori dapat dilihat pada Tabel 5 dimana terdapat enam Faktor dengan indikator yang telah disesuaikan. Dimensi penentu kepuasan kerja karyawan sebelum faktoring adalah (1) evaluasi dan promosi, (2) kompensasi dan tunjangan, (3) konten pekerjaan, (4) lingkungan kerja, (5) pimpinan, dan (6) hubungan interpersonal. Sedangkan dimensi penentu kepuasan kerja karyawan setelah faktoring menjadi (1) kompensasi dan dukungan, (2) lingkungan dan peluang karir, (3) evaluasi dan tanggung jawab, (4) otonom, (5) komunikasi, dan (6) konten pekerjaan. Walaupun keduanya tetap terdiri dari enam dimensi, namun penamaan dimensi menjadi berubah menyesuaikan dengan indikator yang didapatkan dari hasil analisis faktor konformatori.

Faktor 1 diberi penamaan kompensasi dan dukungan, yang terdiri dari tujuh indikator yaitu sistem kompensasi yang adil, bonus berdasarkan kinerja, kesesuaian gaji dengan posisi pekerjaan, apresiasi atau pengakuan hasil kerja, instruksi pimpinan yang jelas dalam penyelesaian tugas, kesesuaian pekerjaan dengan pelatihan kerja dan kerjasama dan dukungan dari departemen lain.

Tabel 5. Perbandingan Faktor dan Indikator Sebelum Sesudah Factoring

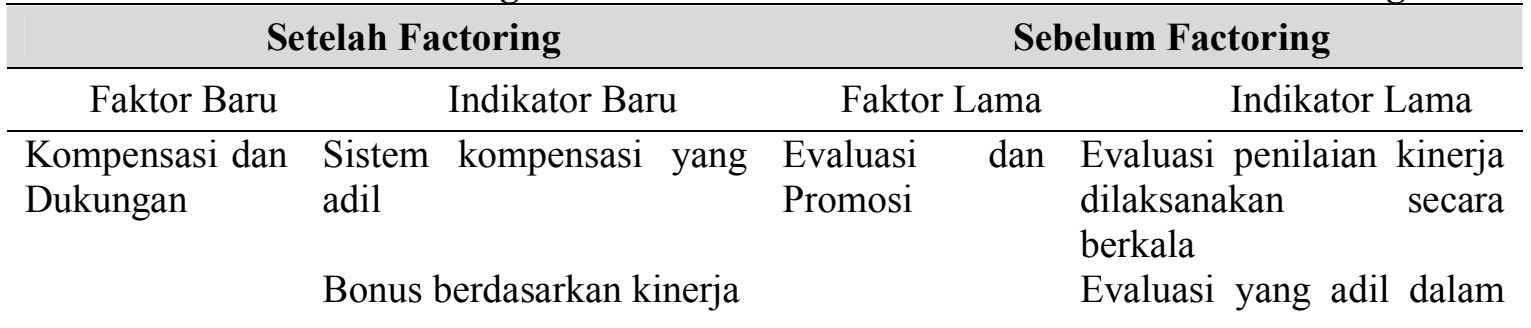




\begin{tabular}{|c|c|c|c|}
\hline \multicolumn{2}{|c|}{ Setelah Factoring } & \multicolumn{2}{|c|}{ Sebelum Factoring } \\
\hline & $\begin{array}{l}\text { Kesesuaian gaji dengan } \\
\text { posisi pekerjaan }\end{array}$ & & $\begin{array}{l}\text { penilaian kinerja tahunan } \\
\text { Peluang promosi yang adil }\end{array}$ \\
\hline & $\begin{array}{l}\text { Apresiasi atau pengakuan } \\
\text { hasil kerja } \\
\text { Instruksi pimpinan yang } \\
\text { jelas dalam penyelesaian } \\
\text { tugas }\end{array}$ & & $\begin{array}{l}\text { Kriteria evaluasi dengan } \\
\text { metode yang benar } \\
\text { Evaluasi sebagai } \\
\text { pengambilan keputusan }\end{array}$ \\
\hline & $\begin{array}{l}\text { Kesesuaian pekerjaan } \\
\text { dengan pelatihan kerja }\end{array}$ & & $\begin{array}{l}\text { Hasil evaluasi sebagai } \\
\text { motivasi perbaikan dan } \\
\text { peningkatan kinerja }\end{array}$ \\
\hline & $\begin{array}{l}\text { Kerjasama dan dukungan } \\
\text { dari departemen lain }\end{array}$ & & $\begin{array}{l}\text { Peluang perkembangan } \\
\text { karir }\end{array}$ \\
\hline \multirow[t]{4}{*}{$\begin{array}{l}\text { Lingkungan dan } \\
\text { Peluang Karir }\end{array}$} & $\begin{array}{l}\text { Hasil evaluasi sebagai } \\
\text { motivasi perbaikan dan } \\
\text { peningkatan kinerja }\end{array}$ & $\begin{array}{l}\text { Kompensasi dan } \\
\text { Tunjangan }\end{array}$ & $\begin{array}{l}\text { Sistem kompensasi yang } \\
\text { adil }\end{array}$ \\
\hline & $\begin{array}{l}\text { Peluang perkembangan } \\
\text { karir }\end{array}$ & & $\begin{array}{l}\text { Jumlah tunjangan sesuai } \\
\text { standar } \\
\text { pemerintah }\end{array}$ \\
\hline & $\begin{array}{l}\text { Peluang mempelajari } \\
\text { pekerjaan sesuai skill }\end{array}$ & & Bonus berdasarkan kinerja \\
\hline & $\begin{array}{l}\text { Peluang beradaptasi } \\
\text { dengan pekerjaan } \\
\text { Lingkungan kantor yang } \\
\text { nyaman } \\
\text { Keamanan atau kestabilan } \\
\text { kondisi perusahaan } \\
\text { Kerjasama dan dukungan } \\
\text { rekan kerja sesama } \\
\text { departemen }\end{array}$ & & $\begin{array}{l}\text { Kesesuaian gaji dengan } \\
\text { kinerja } \\
\text { Kesesuaian gaji dengan } \\
\text { posisi pekerjaan } \\
\text { Terdapat program } \\
\text { pelatihan kerja } \\
\begin{array}{l}\text { Kesesuaian pekerjaan } \\
\text { dengan pelatihan kerja }\end{array}\end{array}$ \\
\hline \multirow[t]{6}{*}{$\begin{array}{l}\text { Evaluasi dan } \\
\text { Tanggung jawab }\end{array}$} & $\begin{array}{l}\text { Evaluasi yang adil dalam } \\
\text { penilaian kinerja tahunan }\end{array}$ & $\begin{array}{l}\text { Konten } \\
\text { Pekerjaan }\end{array}$ & $\begin{array}{l}\text { Diberikan kemandirian } \\
\text { dalam bekerja }\end{array}$ \\
\hline & Peluang promosi yang adil & & $\begin{array}{l}\text { Tanggung jawab yang } \\
\text { dimiliki atau diemban }\end{array}$ \\
\hline & $\begin{array}{l}\text { Kriteria evaluasi yang } \\
\text { benar }\end{array}$ & & $\begin{array}{l}\text { Tugas dan tanggung jawab } \\
\text { yang bervariasi }\end{array}$ \\
\hline & $\begin{array}{l}\text { Evaluasi sebagai } \\
\text { pengambilan keputusan }\end{array}$ & & $\begin{array}{l}\text { Pencapaian hasil kinerja } \\
\text { sesuai standar }\end{array}$ \\
\hline & $\begin{array}{l}\text { Tanggung jawab yang } \\
\text { dimiliki atau diemban }\end{array}$ & & $\begin{array}{l}\text { Hasil pekerjaan yang } \\
\text { berguna bagi perusahaan }\end{array}$ \\
\hline & $\begin{array}{l}\text { Hasil pekerjaan yang } \\
\text { berguna bagi perusahaan }\end{array}$ & & $\begin{array}{l}\text { Peluang mempelajari } \\
\text { pekerjaan sesuai skill }\end{array}$ \\
\hline \multirow[t]{2}{*}{ Otonom } & $\begin{array}{l}\text { Kesesuaian gaji dengan } \\
\text { kinerja }\end{array}$ & & $\begin{array}{l}\text { Peluang beradaptasi } \\
\text { dengan pekerjaan }\end{array}$ \\
\hline & $\begin{array}{l}\text { Kemandirian dalam } \\
\text { bekerja }\end{array}$ & & $\begin{array}{l}\text { Apresiasi atau pengakuan } \\
\text { hasil kerja }\end{array}$ \\
\hline Komunikasi & Komunikasi secara verbal & $\begin{array}{l}\text { Lingkungan } \\
\text { Kerja }\end{array}$ & $\begin{array}{l}\text { Lingkungan kantor yang } \\
\text { nyaman }\end{array}$ \\
\hline
\end{tabular}




\section{KERJA KARYAWAN HOTEL}

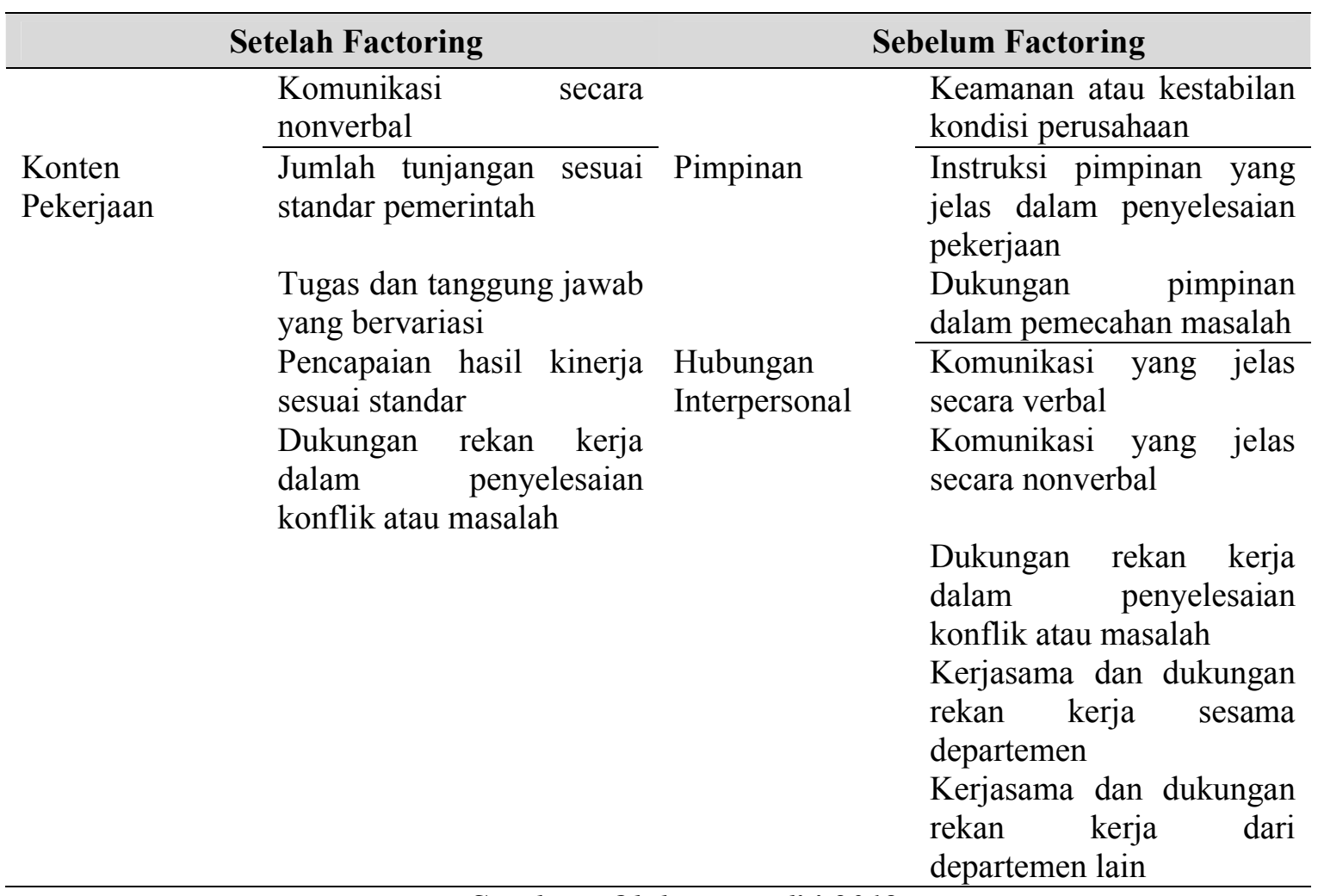

\section{Sumber : Olahan peneliti 2018}

Faktor 3 diberi penamaan evaluasi dan tanggung jawab, yang terdiri dari enam indikator yaitu evaluasi yang adil dalam penilaian kinerja tahunan, peluang promosi yang adil, kriteria evaluasi yang benar, evaluasi sebagai pengambilan keputusan, tanggung jawab yang dimiliki atau diemban dan hasil pekerjaan yang berguna bagi perusahaan. Faktor 4 diberi penamaan otonom, yang terdiri dari dua indikator yaitu kesesuaian gaji dengan kinerja dan kemandirian dalam bekerja.

Faktor 5 diberi penamaan komunikasi, yang terdiri dari dua indikator yaitu komunikasi yang jelas secara verbal dan komunikasi yang jelas secara non-verbal. Faktor 6 diberi penamaan konten pekerjaan, yang terdiri dari empat indikator yaitu jumlah tunjangan sesuai standar peraturan pemerintah, tugas dan tanggung jawab yang bervariasi, pencapaian hasil kinerja sesuai standar, dan dukungan rekan kerja dalam penyelesaian konflik atau masalah.Faktor 2 diberi penamaan lingkungan dan peluang karir, yang terdiri dari tujuh indikator yaitu hasil evaluasi sebagai motivasi perbaikan dan peningkatan kinerja, peluang perkembangan karir, peluang mempelajari pekerjaan sesuai skill, peluang beradaptasi dengan pekerjaan, lingkungan kantor yang nyaman, keamanan atau kestabilan kondisi perusahaan dan kerjasama dan dukungan rekan kerja sesama departemen.

\section{KESIMPULAN}

Faktor utama yang menentukan kepuasan kerja karyawan Restoran Cinnamon, Mandarin Oriental, Jakarta adalah evaluasi sebagai pengambilan keputusan dan lingkungan kantor yang nyaman. Demografik yang berbeda seperti jenis kelamin, departemen tempat bekerja, pendidikan dan rentang usia menunjukkan perbedaan pada faktor utama yang menentukan kepuasan kerja seorang karyawan. Karyawan pria lebih mementingkan lingkungan kantor yang nyaman, sedangkan karyawan wanita lebih menekankan pada pentingnya evaluasi penilaian kerja secara berkala. Begitu juga 
dengan rentang usia, bagi karyawan usia muda yang tergolong fresh graduate, peluang perkembangan karir lah yang paling penting, namun untuk karyawan yang sudah memasuki usia 30an ternyata evaluasi yang adil jauh lebih penting dibandingkan sekedar peluang karir.

Faktor faktor inilah yang kemudian harus diperhatikan oleh pihak pengelola hotel, baik manajemen maupun posisi level managerial. Dengan memahami faktor yang menentukan seorang karyawan puas, maka akan membantu untuk meningkatkan kinerja perusahaan. Hal ini sejalan dengan Badriyah (2015) yang mengatakan bahwa karyawan yang merasa puas terhadap pekerjaannya akan memiliki komitmen yang tinggi terhadap pekerjaan dan perusahaannya. Selain itu, karyawan yang puas juga akan menunjukkan perilaku yang baik ketika bekerja, baik kepada tamu maupun kepada rekan kerja (Pattnaik \& Suvadarshini, 2015).

\section{Saran}

Manajemen hotel sebaiknya menciptakan lingkungan kerja yang nyaman seperti split room dengan suasana, suhu, cahaya dan penerangan yang baik. Adapun bagi karyawan pria lingkungan kerja menjadi hal yang penting. Manajemen hotel juga harus memastikan bahwa evaluasi benar dijalankan secara berkala dan adil yang dibarengi dengan sistem kompensasi yang adil juga. Penelitian selanjutnya dapat menambah jumlah responden untuk penyebaran kuesioner agar mendapatkan responden yang lebih banyak, seperti melibatkan karyawan dari departemen lain (housekeeping, front office, back of the house).

\section{DAFTAR PUSTAKA}

Alhamdi, R. (2018). Pengaruh Kompetensi dan Motivasi Terhadap Kinerja Karyawan Dengan Kepuasan Kerja Sebagai Variabel Moderasi di Patra Semarang Convention Hotel. Jurnal Pariwisata Pesona, 3(1), 57-68.

AliAbadi, S. M., AliAkbar, S. M., \& Fathi, K. (2014). A Study to Determine the
Dimensions of Job Satisfaction, Job Turnover Tendency, Individual Personalities and Psychological WellBeing in Tehran City Hall. Management Science Letters, 4, 1153 1160.

An, J., Cha, S., Moon, H., Ruggiero, J., \& Jang, H. (2014). Factors Affecting Job Satisfaction of Immigrant Korean Nurses. Journal of Transcultural Nursing, 1-10.

Azeem, S. M., \& Akhtar, N. (2014). Job Satisfaction and Organizational Commitment among Public Sector Employees in Saudi Arabia. Journal of Business and Social Science, 5(7), 127 - 133.

Badriyah, M. (2015). Manajemen Sumber Daya Manusia. Bandung: CV Pustaka Setia.

Bungin, B. (2017). Penelitian Kualitatif Komunikasi, Ekonomi, Kebijakan Publik, dan Ilmu Sosial Lainnnya. Jakarta: Kencana.

Dando, D. D., Abate, G. L., \& Mola, A. A. (2017). Factor Analysis of Academic Staff Satisfaction in Dire Dawa University, Ethiopia. Science Journal of Education, 5(2), 71 - 81.

Darmawati, A., Hidayati, L. N., \& Herlina, D. (2013). Pengaruh Kepuasan Kerja dan Komitmen Organisasi terhadap Organizational Citizenship Behavior. Journal Economia, 9(1), 10-17.

Earlike, F \& Atalina, T. (2016). Pentingnya Peranan Skill dan Menu Knowledge Waiter/ Waiters Terhadap Kepuasan Pelanggan di Food and Beverage Service Departement. Jurnal Pariwisata Pesona 18(1).

Einolander, J. (2015). Evaluating Organizational Commitment in Support of Organizational Leadership. Procedia Manufacturing, 3, 668 - 673.

Eldridge, S., Lancaster, G., Campbell, M., Thabane, L., Hopewell , S., Coleman, C., \& Bond, C. (2016). Defining Feasibility and Pilot Studies in Preparation for Randomised Controlled 
Trials: Development of a Conceptual Framework. PLoS ONE, 11(3), 1-22.

Fanning, K. 24 July 2017. Pay, Recruitment and Turnover: Trends to Know in 2017. Hämtat från Compdata Surveys.

Hartono , B., \& Setiawan, R. (2013). Pengaruh Komitmen Organisasional terhadap Kepuasan Kerja Karyawan Paparon's Pizza Citi of Tomorrow. AGORA, 1(1), 1-8.

Hashim, R. (2015). Levels of Job Satisfaction among Engineers in a Malaysian Local Organization. Procedia Social and Behavioral Sciences 195, 175 - 181.

Masum, A., Azad, A., \& Beh, L. (2015). Determinants of Academic's Job Satisfaction: Empirical Evidence from Private Universities in Bangladesh. PLoS ONE 10(2), 1-15.

Munir, R., \& Rahman, R. (2016). Determining Dimensions of Job Satisfaction using Factor Analysis. Procedia Economic and Finance 37, 488 - 496.

Pan, F. C. (2015). Practical Application of Importance - Performance Analysis in Determining Critical Job Satisfaction Factors of a Tourist Hotel. Tourism Management 46, 84 - 91.

Pattnaik, M., \& Suvadarshini, A. (2015). Measuring Employee Satisfaction through Factor Analysis: A Case of State Bank of India (SBI) in Bhubaneswar." Journal of Business and Management Sciences, 3(1), 45 52.

Respondent A. 2018, June. Personal communication. (Jenny Chandra, Interviewers)

Respondent B. 2018, June. Personal communication. (Jenny Chandra, Interviewers)

Respondent C. 2018, June. Personal communication. (Jenny Chandra, Interviewers)

Saputro, H., Fathoni, A., \& Minarsih, M. (2016). Pengaruh Kepuasan Kerja Ketidakamanan Kerja dan Komitmen
Organisasi terhadap Intensi Pindah Kerja (Turnover Intention). Journal of Management, 1-14.

Sekaran, U., \& Bougie, R. (2013). Research Methods for Business: A Skill-Building Approach. Chichester: John Wiley \& Sons.

Siregar, S. (2015). Metode Penelitian Kuantitatif: Dilengkapi Perbandingan Perhitungan Manual \& SPSS. Jakarta: Prenadamedia Group.

Sudaryono. (2016). Metode Penelitian Pendidikan. Jakarta: Prenadamedia Group.

Sujarweni, V. (2014). Metodologi Penelitian. Yogyakarta: Pustaka Baru Press.

Tomazevi, N., \& Aristovnik, J. A. (2014). Factors Influencing Employee Satisfaction in the Police Service: The Case of Slovenia. Personnel Review, 209-227. 